\title{
Direct and indirect impacts of climate change on wheat yield in the Indo-Gangetic plain in India
}

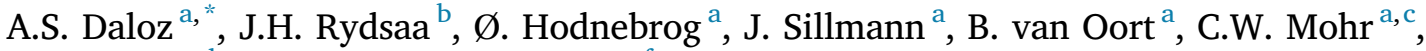 \\ M. Agrawal ${ }^{\text {d }}$, L. Emberson ${ }^{\text {e }}$, F. Stordal ${ }^{f}$, T. Zhang ${ }^{g}$ \\ ${ }^{\text {a }}$ Center for International Climate Research, Oslo, Norway \\ ${ }^{\mathrm{b}}$ Department of Physics and Technology, The Arctic University of Norway, Troms $\phi$, Norway \\ ${ }^{\mathrm{c}}$ Norwegian Institute of Bioeconomy Research, Oslo, Norway \\ ${ }^{\mathrm{d}}$ Department of Botany, Banaras Hindu University, Varanasi, India \\ ${ }^{\mathrm{e}}$ Environment and Geography Department, University of York, Heslington, York, UK \\ ${ }^{\mathrm{f}}$ Department of Geosciences, University of Oslo, Oslo, Norway \\ ${ }^{\mathrm{g}}$ Institute of Atmospheric Physics, Chaoyang, Beijing, China
}

\section{A R T I C L E I N F O}

\section{Keywords:}

Wheat yield

Climate change

Irrigation

Indo-gangetic plain

Climate model

Crop model

\begin{abstract}
A B S T R A C T
The Indo-Gangetic Plain (IGP) is one of the main wheat-production regions in India and the world. With climate change, wheat yields in this region will be affected through changes in temperature and precipitation and decreased water availability for irrigation, raising major concerns for national and international food security. Here we use a regional climate model and a crop model to better understand the direct (via changes in temperature and precipitation) and indirect (via a decrease in irrigation availability) impacts of climate change on wheat yields at four sites spread across different states of the IGP: Punjab, Haryana, Uttar Pradesh and Bihar. The results show an increase in mean temperature and precipitation as well as maximum temperature during the growing season or Rabi season (November-April). The direct impact of climate change, via changes in temperature and precipitation, leads to wheat yield losses between $-1 \%$ and $-8 \%$ depending on the site examined. Then, the indirect impact of climate change is examined, considering the impact of climate change on water availability leading to a decrease in irrigation. In this case, the yield losses become significant and much higher, reaching $-4 \%$ to $-36 \%$ depending on the site examined and the irrigation regime chosen $(6,5,3$ or 1 irrigations). This work shows that the indirect impacts of climate change may be more detrimental than the direct climatic effects for the future wheat yields in the IGP. It also emphasizes the complexity of climatic risk and the necessity of integrating indirect impacts of climate change to fully assess how it affects agriculture and choose the adequate adaptation response.
\end{abstract}

\section{Introduction}

Wheat plays a critical role for national food security in India but also globally as it is the second largest producer in the World, contributing to $13 \%$ of the global wheat supply (Zaveri and Lobell [49]). With temperatures very likely to rise in the coming years, a fall in yield is likely for many wheat-production regions in the World [3] and has been projected for several countries such as Egypt [1], Iran [37], Russia and India [50]. Here, we focus on the Indo-Gangetic Plain (IGP), which includes India's major wheat-producing regions: Uttar Pradesh, Punjab and Harayana. The predominant position of the IGP is the result of agricultural policies taken during the Green Revolution in the 1960s and 1970s, enabling rice and wheat to emerge as major crops for this region [24]. However, as Sekar and Pal [41] showed, wheat and rice productivity growth has already decelerated over the last decades, raising major concerns for national and international food security. In this context, appropriate adaptation responses might be necessary, it is therefore important to better understand how wheat yield production is changing and how it could be affected by additional stresses resulting from climate change in the future.

Prior work using single models or multi-model ensembles such as the Climate Model Intercomparison Project Phase 5 (CMIP5) or the Coordinated Regional Climate Downscaling EXperiment (CORDEX) have shown that, with climate change, mean and extreme temperatures will increase

\footnotetext{
* Corresponding author.

E-mail address: anne.sophie.daloz@cicero.oslo.no (A.S. Daloz).
} 
in the IGP in the future $[9,10,39,47]$. The most pessimistic projections show an increase in mean temperature up to over $6^{\circ}$ by 2080 compared to present-day [9]. For mean and extreme precipitation, the projections are more heterogeneous, both for the amplitude and the sign of the change. Chaturvedi et al. [10] looked at different projections and scenarios in CMIP5 models and showed a multi-model mean increase in precipitation in the IGP, of around 10\% for the RCP 8.5 scenario by 2030 s and $20 \%$ by $2080 \mathrm{~s}$. Bal et al. [7] found similar results with a regional climate model. In addition, several studies have shown a potential for heavier precipitation events [10,11] and drought [35] over India.

Previous studies have also investigated the impact of climate change on wheat yield in India showing a wide range of results depending on the stresses considered. To quantify the impact on crop productivity by both direct climate parameters like temperature and precipitation changes, as well as the indirect effects by alterations in management such as irrigation, crop models are very useful. Here, we used the Decision Support System for Agro-technology Transfer (DSSAT) modelling system, which has been applied over different regions for a wide variety of crops [19-21] as crop models are frequently applied to predict crop growth and development in response to water availability, soil characteristics, management, crop varieties and climate [e.g. 4, 6, 15, 22, 38, 45]. Over India, Attri and Rathore [4] examined the impact of changes in temperature and $\mathrm{CO}_{2}$ in North-West India and found a potential wheat yield enhancement, up to $+37 \%$ under rainfed conditions and $+28 \%$ under irrigated conditions by the middle of the century. They also suggested that, when reaching a temperature increase beyond $3{ }^{\circ} \mathrm{C}$, the increase in temperature would cancel the impact of enhanced $\mathrm{CO}_{2}$. Under equivalent conditions Lal et al. [26] found similar results in North West India with an increase in wheat yield up to $+21 \%$. Additionally, they found that under a shortage in water conditions, a decline in wheat yield would be observed. Kumar et al. [23] recently looked at the impact of changes in temperature and rainfall in India and also projected a wheat yield reduction, up to $-25 \%$ by 2080 . Lobell et al. [29] focused on the IGP and on extreme heat effects on wheat senescence, they also reported a potential reduction of up to $-20 \%$ in certain pockets of the region. Zhao et al. [50] realized a global study on the impact of climate change on four crops including wheat. In India, all the models predict a decrease in wheat yield, up to $-15 \%$ by 2100 for the most pessimistic model. This wide spread of estimates shows that there still exists considerable uncertainty regarding the effects of climate change on the future crop production in this region, and one major source of uncertainty is related to effects of future changes in precipitation.

Several countries or regions count on irrigation as an adaptation response for a shortage in water due to the impacts of climate change. For example, in China Lv et al. [31] looked at the impact of climate change on regional winter wheat production regions and showed that under rainfed conditions, some regions show a decrease, while under full-irrigation conditions yields are expected to increase almost everywhere. In arid regions where spring wheat is growing, Ding et al. [12] have also seen a drastic decline in wheat under climate change and a deficit in irrigation. To mitigate the effect of temperature or the lack of precipitation on crop yield, farmers in the IGP already widely use irrigation [49], and as much as $85 \%$ of the wheat land area is irrigated [23]. The development of irrigation systems is a key measure taken during the green revolution to enable wheat cropping during the dry Rabi season [15], however the quality of irrigation may differ depending on the part of the region examined [5]. Looking at historical data, Zaveri and Lobell [49] have shown that there are already a lot of constraints on irrigation in India, limiting the potential for yield gains in the face of additional warming. In the future, the irrigation potential could be even more limited by the adverse effects of climate change on rain, snow and glaciers. An increase in annual runoff has been suggested by Gosain et al. [17] and Lutz et al. [30] for the Ganges and Indus river basins respectively, however as it might not happen during the growing season both studies predict a potential limitation in water availability and therefore restrictions on irrigation. This indirect climate impact on crop production is an important aspect often overlooked in climate impact studies.

Most climate projections in the literature rely on climate models with coarse spatial resolution $(>50 \mathrm{~km}$ ). To better assess the impact of climate change on crop yields, there is a need for climate simulations at higher spatial resolutions. In this study, we produce and analyze higher resolution climate model simulations $(15 \mathrm{~km} \times 15 \mathrm{~km})$ to investigate future changes in temperature and precipitation during the different growing stages of wheat for the Rabi season in the IGP. Then, these data are incorporated into a crop model to investigate how climate change, through changes in temperature and precipitation, could affect wheat yields in this region. Most of the studies looking at the impact of climate change on wheat yield in India are focusing on the direct impact of climate change (via temperature, precipitation or $\mathrm{CO}_{2}$ ). While this aspect is important and also under consideration in this work, some have argued that there is also a need for more complex studies [25]. Here, in addition to the direct impact of climate change, we will also consider an indirect impact through changes in the water availability for irrigation. In the next section, the climate and the crop models are described. Section 3 shows future changes in temperature and precipitation. The direct and indirect impacts of climate change on wheat yield are examined in Sections 4 and 5. Finally, the last section discusses the results and gives some concluding remarks.

\section{Data and methodology}

\subsection{Study area}

The Indo-Gangetic Plain (IGP), shown in Fig. 1, is the main wheat production zone in India [36] and in the World [13]. This fertile plain is named after the Indus and Ganges rivers that pass on this region and encompasses northern regions of the Indian subcontinent. In the IGP, wheat is typically sown in autumn, between mid-November (north-west India) and mid-December (central India), and harvested in spring, late March to mid-April. This period defines one of the growing seasons, also called Rabi season. According to the Institute of Agriculture (BHU) different types of wheat are cultivated in this region, including winter and spring wheat varieties. The experiments for our investigations will use two different types of spring wheat.

Spatial maps of the differences between the RCP8.5 scenario (2046-2065) and the present climate (1986-2005) in: a) mean precipitation $\left(\mathrm{mm}\right.$.day $\left.{ }^{-1}\right)$ and $\left.\mathrm{b}\right)$ mean surface temperature over India simulated by the climate model WRF. The dashed lines indicate when the differences are statistically significant at the $99 \%$ level using a t-test. Blue dots show the placement of the DSSAT simulation sites spread across the IGP. The areas encompassed by the black and white boxes represent the IGP.

\subsection{Regional climate model}

The regional Weather Research and Forecasting (WRF) model version 3.7.1 ([44]) has been used to downscale global climate model outputs over the IGP for this study. Two domains have been set up, one with $45 \mathrm{~km} \times 45 \mathrm{~km}$ horizontal resolution, covering large parts of South Asia, and one with $15 \mathrm{~km} \times 15 \mathrm{~km}$ resolution, covering all of India and most of the Tibetan Plateau. The model was set up with 35 vertical levels, and spectral nudging was applied for temperature, horizontal winds and geopotential height in the outermost ( $45 \mathrm{~km}$ resolution) domain. Simulations have been carried out for one present-day (1986-2005) and one future time period (2041-2060). The future period has been simulated for a pessimistic scenario in terms of greenhouse gas emissions, the Representative Concentration Pathway 8.5 [46]. Each time period has been run in one-year time slices, each re-initialized in December of the previous year to allow one month of spin-up. An overview of the parameterization schemes is given in Table A1. Meteorological initial/boundary conditions and sea-surface temperatures for the WRF model were taken from a fully coupled global climate simulation using the National Center for Atmospheric Research (NCAR) Community Earth 
a) Mean Precipitation
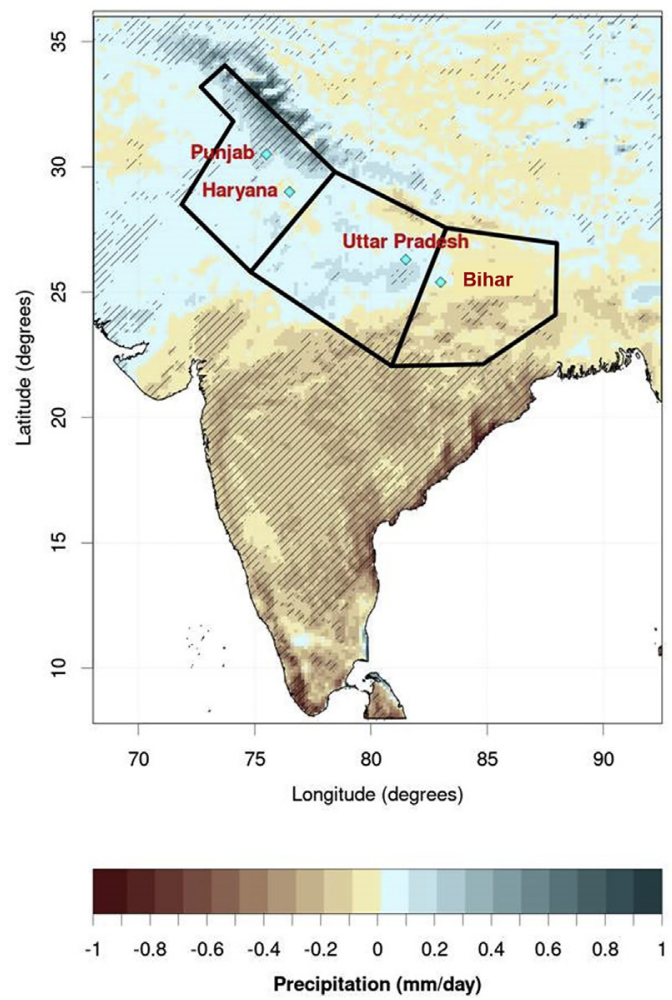

b) Mean Temperature
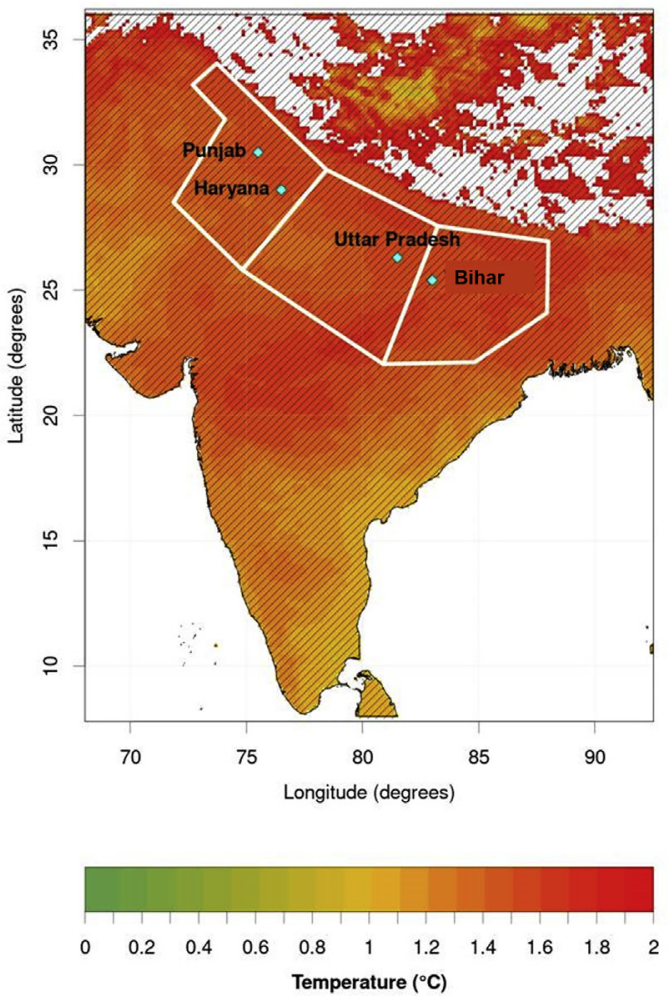

Fig. 1. Climatic changes between the RCP8.5 scenario and present-day.

System Model (CESM1.0.4) [16], as described by Hodnebrog et al. [18]. In this study, we only used one climate model due to the vast computation resources needed for a multi-model experiment. However, we compared the outputs of our simulations with multiple datasets: observations and a multi-model ensemble of regional climate models (Supplemental Material, [32]). This comparison allowed confidence in the representation of the climate by our model. The outputs from the climate simulations were then introduced into the crop model to simulate the impact of climate change on wheat yield.

\subsection{Crop model}

The Decision Support System for Agrotechnology Transfer (DSSAT) Crop System Model v 4.7 [19,20] is a modelling system widely used to simulate growth and development of crops under different management, climatic and soil conditions. The DSSAT modelling system comprises several models for various crops, among them three different wheat models. Here, we have chosen the CROPSIM-CERES-Wheat model for simulating wheat growth and development. The system can be adapted to test and evaluate different management strategies and to estimate the effects of changing environmental conditions due to i.e., climate change. Previous versions of this wheat model have been applied in the IGP and thorough calibration and validation showed that the model was suitable for this region [e.g., 38, 45]. Four different sites have been chosen across the IGP to represent each of the major wheat growing states (Punjab, Haryana, Uttar Pradesh and Bihar) using both present and future climate data from the WRF simulations. The sites are shown in Fig. 1 with the blue dots. Sites were chosen based on considerations of representing the climatic conditions and changes for both scenarios, in addition to representing typical and realistic soil conditions for crop land across the IGP, matching land use types and altitudes with the climate model. Although four single sites can never fully represent the diversity of crop growth in the IGP, our aim here is to present general and representative crop yields across the IGP rather than site-specific estimates and have chosen our experimental setup accordingly. Wheat yields are thus simulated in an experimental setup designed to specifically investigate the crops' sensitivity to changes in the climatic conditions and irrigation due to changes in water availability.

Even though we are using outputs from a high-resolution regional climate model compared to previous studies, this is still fairly coarse inputs for a site-specific crop model such as DSSAT. Rather than focusing on site-specific annual crop yield estimates, the setup is designed to obtain a robust estimate of average yields representative for each region. We simulate 19 growing seasons for each climate scenario, and the results from each time period and scenario are presented as averages of each 19-year period. We choose to focus on spring wheat, a commonly grown crop in the IGP during the Rabi season. To account for variations in sensitivity and development of crop cultivars, each period is simulated for two wheat cultivars (Triticum aestivum L., var HD-2967 and var HD2329). Both cultivars have previously been calibrated and validated against IGP site measurements in earlier versions of the DSSAT-CERESWheat modelling system to investigate environmental effects such as precipitation [45] and nitrogen and management effects on crop yields in the IGP [38]. Here, we apply these cultivars for the same purpose and thus use the calibrated cultivars to ensure the qualities of the wheat varieties simulated here is realistic for the area and reference climate. Cultivar calibration is for example used to define properties such as vernalization requirements, heat required and limits for growth stages. To ensure the isolation of the effect of climate and irrigation changes on the crop yields, the experimental setup with respect to management is the same for both cultivars, at all sites, and is based on the "best practice" recommendations for growing wheat in the IGP according to the Indian Directorate of Wheat development [14]. This ensures a realistic, objective management plan across all sites. For comparability, we assume that the 'best practice' management advice developed for today's conditions, are still valid under future conditions. Details of the management plan are listed in Table A2. In addition to the management plan and all other environmental conditions, such as $\mathrm{CO}_{2}$ level, soil nutrient levels, and 


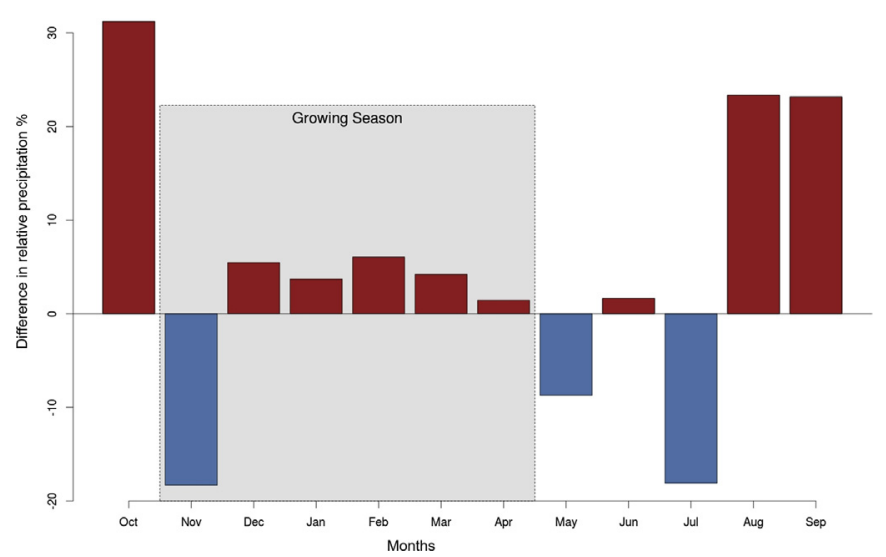

Fig. 2. Relative changes in monthly mean precipitation.

irrigation methods are kept the same across all sites, time periods and cultivars. All planting occurs in accordance with recommendations on the 15th of November. A modest irrigation plan (for all number of applications), fertilization and herbicides are applied in accordance with recommendations throughout the growing season. Harvest is set to automatically occur at maturity and as such adjusts the length of the growing season in accordance with the climatic conditions. In accordance with literature and observations across the IGP, the soils are assumed to be sandy clay loam of alluvial origin, of $2 \mathrm{~m}$ depth. The soil data profiles are from the DSSAT v4.7 soil database. Further details about the sites and simulation setup are found in Table A2.

\section{Results}

\subsection{Impact of climate change on the environment in the IGP}

The projected changes in mean precipitation between the scenario RCP8.5 and the present climate indicate an increase in precipitation, up to +0.7 mmday $^{-1}$ over most of the IGP (Fig. 1a). Over the southern part of the IGP, some locations show a decrease in precipitation reaching -0.4 mmday $^{-1}$. The four sites used in the crop model are in areas where precipitation is increasing, but not significantly, except for the site in Punjab. Furthermore, this increase does not mean that precipitation is increasing for every month of the growing season, the changes in precipitation may vary depending on the month examined, as shown in Fig. 2. During the growing season, precipitation is substantially decreasing in November $(-18 \%)$ and increasing to a small extent during the rest of the season $(<+10 \%)$. This large decrease happens during the phase of sowing and germination, a period where the plants need a high amount of water. This could cause an important stress for the plants.

Histogram of the relative changes in monthly mean precipitation (\%) between the scenario RCP8.5 and the present climate simulated by the climate model WRF. The results are averaged over the IGP. Positive (negative) anomalies are in red (blue). The time period of the growing season is highlighted by a grey square.

A significant increase in mean temperature (up to $2^{\circ} \mathrm{C}$ ) can be seen over the entire IGP in the future projections (Fig. 1b), which can represent an additional stress factor for the plants. Furthermore, Fig. 3 presents a time series of maximum temperature during the growing season for the present climate (green) and the RCP8.5 scenario (orange). The different parts of a typical growing season are indicated along the $\mathrm{x}$-axis as well as their optimal (dashed lines) and critical (grey lines) range of temperatures. The figure illustrates how the different phases of the growing season can be affected by warmer temperatures, assuming that the length of the growing season is remaining the same in the future for illustrative purposes. This is an approximation as this is not the case in our experiments, which regulate the length of the growing season in response to the climatic conditions. In our simulations, we find a shortening of the

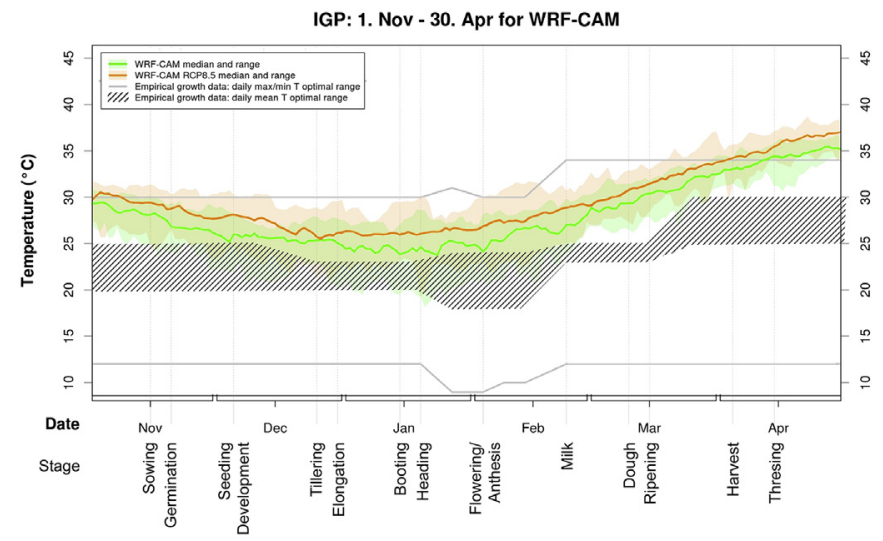

Fig. 3. Evolution of maximum temperature during the growing season.

growing season of about 4 days (ranging from 2.9 to 5.2 depending on site) in the future RCP8.5 scenario as compared to the present-day time period. Also, the use of a range of cultivars, coupled with breeding programs that improve the heat tolerance of wheat $[34,40]$, make it hard to pinpoint the exact optimal and critical temperature limits above which wheat yields over a large area such as the IGP are affected, both now and in the future. As such, these critical periods should be considered as estimates. A critical period for wheat development is during and after flowering as this phase determines the number and the filling of grains [29]. However, plants are generally sensitive to an increase in ambient temperatures when it surpasses optimum growing conditions. The period before flowering, between stem elongation and the booting stage defines the wheat productivity. During this period, the wheat develops very fast and therefore needs more resources. The plant could therefore also be very sensitive to climate change during this period.

Time series of $\mathrm{T}_{\max }$ over the IGP during the growing season (November-April) for the present climate (green) and the RCP8.5 scenario (orange), as simulated by the regional climate model WRF. The different stages of the growing season are indicated under the $x$-axis. The grey dashed lines indicate the empirical optimal range for the growth of wheat. The grey lines indicate the empirical critical minimum and maximum temperature for the growth of wheat.

As shown in Fig. 3, daily maximum temperatures $\left(\mathrm{T}_{\max }\right)$ increase along the growing season for both the present and future climates. $\mathrm{T}_{\max }$ in the present and future climate are always higher than the optimal range of temperatures. Furthermore, maximum temperatures in the future climate are always warmer than in the present climate, being up to $3^{\circ} \mathrm{C}$ warmer for some dates. Crops are very sensitive to these extreme temperatures during the middle of the growing season (before, during and after flowering), but higher temperatures all along the season also pose stress that can impact wheat yield. $\mathrm{T}_{\max }$ in the present and future climate do not reach the lethal temperature for the plants $\left(47^{\circ} \mathrm{C}\right)$ but they get outside of the critical range at the end of the season. This shows that plants are already under some stress in the present climate. For the multimodel median, $\mathrm{T}_{\max }$ starts to exceed the optimal range threshold in approximately mid of April in present climate (end of harvest) and in future climate already in the beginning of April (start of harvest). For individual years, the critical threshold can be exceeded already as early as mid-March under future climate affecting thus also the ripening stage of wheat. This is indicated by the shading around the multi-year median which illustrates temporal variability over the 20 model years. This means that temperatures in the future climate reach the threshold of critical temperatures sooner than in the present climate, again representing a potential stress for the plants.

\subsection{Direct impact of climate change on wheat yield}

To investigate the effects of future changes in temperature and 
precipitation on wheat yield, simulations have been performed with DSSAT as described in Section 2. The results from these simulations are presented in Table 1, which shows the absolute values for mean harvested yield $\left(\mathrm{kg} \mathrm{ha}^{-1}\right)$ in the present climate and under the RCP8.5 scenario. The table shows the yield under rainfed conditions ( 0 irrigations) and under 3, 5 or 6 irrigations, where the latter is considered as the best practice regime. The table also indicates the standard error for each site, giving an indication on the dispersion of wheat productivity for the different locations. First, looking at the results for the present climate we see that depending on the site examined, wheat yield shows large variations. For example, under rainfed conditions, it varies between $2603 \mathrm{~kg}$ $\mathrm{ha}^{-1}$ for Bihar and $3116 \mathrm{~kg} \mathrm{ha}^{-1}$ for Punjab. Knowing that these sites have the same soil conditions, these differences come from the climatic background. The comparison of rainfed conditions with the next three columns indicating the number of irrigations per day shows the beneficial impact of irrigation. Going from rainfed conditions to 3 irrigations increases wheat yield by around $+25 \%$ for all sites. Then going to 5 or 6 irrigations is generally beneficial for wheat yield, but the relative increase is not as high (5 to 10\%). This shows that irrigation is critical for the cultivation of wheat in this region and that limiting irrigation could have a very important impact on agriculture. This point will be further examined in the next section of the article.

The right part of the table provides the absolute values and the relative changes in wheat yield (\%) between the scenario RCP8.5 and the present climate for a specific irrigation regime (6, 5, 3 or 0 irrigations). All the sites show a decrease in wheat yield under future conditions, ranging between -1 and $-8 \%$ depending on the region and the irrigation regime, however most of them are not statistically significant. The relative losses increase for higher potential yield, i.e. increased irrigation. Thus, rainfed crops seem less sensitive to the stress related to climate change, as the water stress itself causes low crop yields as compared to irrigated conditions. This is also evident from the transpiration rates, which decrease in rainfed conditions as compared to the irrigated ones (not shown). For example, averaged across all sites, the direct impacts of climate on rainfed yields decreases them by $3 \%$ under the RCP 8.5 scenario, and it varies between sites (Table 1 ). If water availability remains high under future conditions, the reduction in wheat yield is still limited to about $5 \%$ under the best practice irrigation scheme. In this context, the next section will add another layer of complexity by including the indirect impact climate change, showing the effect of limited irrigation under future conditions.

\subsection{Combined direct and indirect impacts of climate change on wheat yield}

To investigate one of the indirect impacts of climate change on wheat yield, the potential effects of limited water resources for irrigation, sensitivity simulations using a limited number of irrigation applications were conducted in the present climate and for the scenario RCP8.5. This way of looking at irrigation is rather idealized as the limitations in irrigation could be more adapted to the region, but it still gives interesting insights into one of the indirect impacts of climate change on agriculture. The results of these simulations are shown in Table 2. The left part of the table presents the results for the historical climate and the right part for the scenario RCP8.5. This table does not include standard deviation as the results would be the same as Table 1. First, we can examine the individual impact of limiting irrigation by looking at the results for the present climate. The left part of Table 2 shows absolute values and relative changes for mean harvested yield under 6, 5, 3 and 1 irrigations for the present climate. Going from 6 to 5 irrigations, the decrease in wheat yield varies from -3 to $-7 \%$ for all sites. From 6 to 3 irrigations wheat yield decreases between $-3 \%$ and $-10 \%$. The decrease becomes dramatic for all sites when irrigation is reduced from 6 to 1 , with losses between -27 to $-34 \%$. This time, most of these differences are statistically significant.

Looking at the combination of direct impacts of climate change and indirect impacts through limitations in irrigation, the reductions increase under future climate conditions (i.e. RCP8.5 scenario in Table 2). When reducing the number of irrigations from 6 to 5 , the decrease in wheat yield varies between $-4 \%$ and $-11 \%$. Further reduction to 3 irrigations results in higher wheat loss ranging between $-12 \%$ to $-15 \%$ depending on the site examined. Finally, when reducing from 6 to 1 irrigation in future climate all sites show dramatic losses, which amount to around a third of the crop yield (29-36\%). Compared to reductions in wheat yield caused only by the direct effect of climate change (Table 1 ), the estimated decreases in wheat yields due to both the direct and indirect impacts of climate change are much higher and often statistically significant.

\section{Discussion and conclusion}

This article examines how climate change could directly (via changes in temperature and precipitation) and indirectly (via a decrease in water availability for irrigation) impact wheat yields in the IGP in the future. Here, we use a regional climate model and a crop model to look at the impacts of climate change at four sites spread across four states of the IGP: Punjab, Haryana, Uttar Pradesh and Bihar. The comparison of the present climate and future climate using the RCP8.5 scenario shows an increase in mean temperature (up to $+2^{\circ} \mathrm{C}$ ) as well as $\mathrm{T}_{\max }$ (up to $+3^{\circ} \mathrm{C}$ ) during the different stages of the Rabi season over the IGP. These results agree with previous work from $\mathrm{Wu}$ et al. [47] and Sanjay et al. [39]. During the growing season, temperatures in the present and future climate are often outside of the optimal conditions for wheat, and even

Table 1

Direct effect of climate change on mean harvested wheat yield. Mean harvested wheat yield ( $\mathrm{kg} \mathrm{ha}^{-1}$ ) for the present climate (left) and the RCP8.5 scenario (right) for four sites over the IGP. Standard errors about the mean for each estimate are given in parentheses. The mean harvested wheat yield is derived for different irrigation regimes: from rainfed conditions ( 0 irrigations) to 3, 5 irrigations and best practice (6 irrigations). The right part of the table also includes the relative change (\%) in wheat yield. Changes are derived as the difference between the mean harvested wheat yield for the RCP8.5 scenario and the present climate, for each regime of irrigation (0, 3, 5 or 6 irrigations).

\begin{tabular}{|c|c|c|c|c|c|c|c|c|}
\hline \multirow{2}{*}{$\begin{array}{l}\text { Sites } \\
\text { Irrigations }\end{array}$} & \multicolumn{4}{|c|}{$\begin{array}{l}\text { Average wheat yield ( } \pm \text { sme) } \\
\text { Present climate }\end{array}$} & \multicolumn{4}{|c|}{ Average wheat yield ( \pm sme) RCP 8.5 Scenario } \\
\hline & 0 & 3 & 5 & 6 & 0 & 3 & 5 & 6 \\
\hline Punjab & $3116( \pm 177)$ & $4226( \pm 184)$ & $4378( \pm 223)$ & $4657( \pm 227)$ & $\begin{array}{l}3101( \pm 215) \\
-0.5 \%\end{array}$ & $\begin{array}{l}4032( \pm 184) \\
-5 \%\end{array}$ & $\begin{array}{l}4140( \pm 216) \\
-5 \%\end{array}$ & $\begin{array}{l}4392( \pm 216) \\
-6 \%\end{array}$ \\
\hline Harayana & $2898( \pm 192)$ & $3937( \pm 183)$ & $4108( \pm 219)$ & $4399( \pm 228)$ & $\begin{array}{l}2824( \pm 210) \\
-2 \%\end{array}$ & $\begin{array}{l}3745( \pm 180) \\
-5 \%\end{array}$ & $\begin{array}{l}3913( \pm 213) \\
-5 \%\end{array}$ & $\begin{array}{l}4097( \pm 206) \\
-7 \%\end{array}$ \\
\hline Uttar Pradesh & $2807( \pm 209)$ & $3521( \pm 269)$ & $3699( \pm 156)$ & $3824( \pm 147)$ & $\begin{array}{l}2756( \pm 210) \\
-2 \%\end{array}$ & $\begin{array}{l}3361( \pm 150) \\
-5 \%\end{array}$ & $\begin{array}{l}3556( \pm 132) \\
-4 \%^{a}\end{array}$ & $\begin{array}{l}3664( \pm 122) \\
-4 \%\end{array}$ \\
\hline Bihar & $2603( \pm 192)$ & $3234( \pm 152)$ & $3422( \pm 141)$ & $3564( \pm 131)$ & $\begin{array}{l}2397( \pm 203) \\
-8 \%\end{array}$ & $\begin{array}{l}3143( \pm 140) \\
-3 \%\end{array}$ & $\begin{array}{l}3402( \pm 106) \\
-1 \%\end{array}$ & $\begin{array}{l}3521( \pm 95) \\
-1 \%\end{array}$ \\
\hline All sites & $2856( \pm 97)$ & $3730( \pm 91)$ & $3902( \pm 98)$ & $4111( \pm 99)$ & $\begin{array}{l}2769( \pm 106) \\
-3.0 \%\end{array}$ & $\begin{array}{l}3570( \pm 86) \\
-4.3 \%\end{array}$ & $\begin{array}{l}3753( \pm 89) \\
-3.8 \%\end{array}$ & $\begin{array}{l}3919( \pm 88) \\
-4.7 \%\end{array}$ \\
\hline
\end{tabular}

${ }^{\text {a }}$ Bold, italic font indicates statistically significant changes to a 95\% level based on a Wilcoxon signed rank sum test. 
Table 2

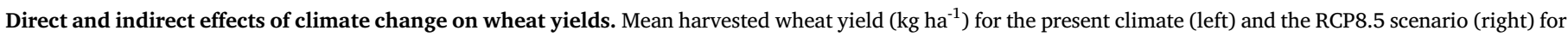

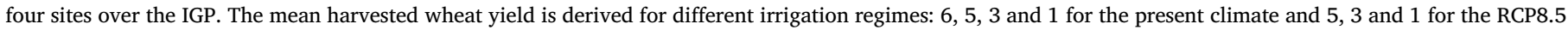

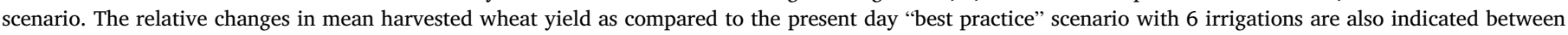

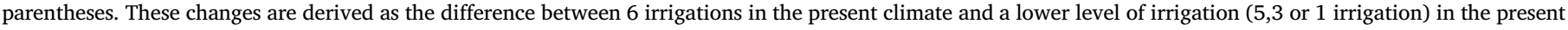
climate and the RCP8.5 scenario.

\begin{tabular}{|c|c|c|c|c|c|c|c|}
\hline \multirow{2}{*}{$\begin{array}{l}\text { Sites } \\
\text { Irrigations }\end{array}$} & \multicolumn{4}{|c|}{$\begin{array}{l}\text { Mean wheat yield (kg ha-1) } \\
\text { Present Climate }\end{array}$} & \multicolumn{3}{|c|}{ Mean wheat yield (kg ha-1; \%) RCP 8.5 Scenario } \\
\hline & 6 & 5 & 3 & 1 & 5 & 3 & 1 \\
\hline Punjab & 4657 & $\begin{array}{l}4378 \\
-6 \%^{a}\end{array}$ & $\begin{array}{r}4226 \\
-9 \%\end{array}$ & $\begin{array}{l}3243 \\
-30 \%\end{array}$ & $\begin{array}{l}4141 \\
-11 \%\end{array}$ & $\begin{array}{l}4032 \\
-13 \%\end{array}$ & $\begin{array}{l}3053 \\
-34 \%\end{array}$ \\
\hline Harayana & 4400 & $\begin{array}{l}4108 \\
-7 \%\end{array}$ & $\begin{array}{l}3937 \\
-\mathbf{1 0} \%\end{array}$ & $\begin{array}{l}2922 \\
-34 \%\end{array}$ & $\begin{array}{l}3914 \\
-11 \%\end{array}$ & $\begin{array}{l}3745 \\
-15 \%\end{array}$ & $\begin{array}{l}2835 \\
-36 \%\end{array}$ \\
\hline Uttar Pradesh & 3824 & $\begin{array}{l}3699 \\
-3 \%\end{array}$ & $\begin{array}{l}3521 \\
-8 \%\end{array}$ & $\begin{array}{l}2790 \\
-27 \%\end{array}$ & $\begin{array}{l}3556 \\
-7 \%\end{array}$ & $\begin{array}{l}3361 \\
-\mathbf{1 2} \%\end{array}$ & $\begin{array}{l}2724 \\
-29 \%\end{array}$ \\
\hline Bihar & 3564 & $\begin{array}{l}3422 \\
-4 \%\end{array}$ & $\begin{array}{r}3234 \\
-9 \%\end{array}$ & $\begin{array}{l}2583 \\
-27 \%\end{array}$ & $\begin{array}{l}3402 \\
-4 \%\end{array}$ & $\begin{array}{l}3143 \\
-12 \%\end{array}$ & $\begin{array}{l}2494 \\
-30 \%\end{array}$ \\
\hline All sites & 4111 & $\begin{array}{r}3902 \\
-5 \%\end{array}$ & $\begin{array}{r}3730 \\
-9 \%\end{array}$ & $\begin{array}{l}1856 \\
-29 \%\end{array}$ & $\begin{array}{l}3753 \\
-9 \%\end{array}$ & $\begin{array}{l}3570 \\
-13 \%\end{array}$ & $\begin{array}{l}2776 \\
-32 \%\end{array}$ \\
\hline
\end{tabular}

${ }^{a}$ Bold, italic font indicates statistically significant changes to a 95\% level based on a Wilcoxon signed rank sum test.

exceed the critical range at the end of the season, during harvest. Under the future warming scenario, this critical threshold is reached sooner than in the present climate, and in some years, already during the ripening stage. Increases in mean precipitation in the IGP are mostly not significant. Interestingly, over a large part of India our simulations show a significant decrease in precipitation while Chaturvedi et al. [10], using CMIP5 models, projected an increase in precipitation over the whole of India. However, they also emphasized the large range of response between the different models and that higher spatial resolution adds further details in the spatial distribution of rainfall. Although our projections are only based on one model, they agree with the projections from other multi-model ensembles (see Appendix A). Liu et al. [28] also showed that the use of different climate downscaling methods can have a large impact on the simulations of the changes in temperature and precipitation and therefore the assessment of simulated crop growth and soil water balance. Such a comparison was not possible to include here but it is an important point for future studies as reliable regional climate projections and information about water management strategies are crucial for estimating water availability for irrigation practices as they are a critical factor for crop yields in the IGP and many other regions in the World.

The climatic changes simulated with regional climate model WRF produce a general wheat yield loss (Section 3.2) for all sites (Punjab, Haryana, Uttar Pradesh and Bihar), ranging between $-1 \%$ and $-8 \%$, when only taking into account the effects of changes in climatic conditions. This decrease in wheat yield agrees with previous work on the direct impact of climate change over India [23,29,48,50]. However, the amplitude of the losses is in the range of the results from the multi-model study of Zhao et al. [50] but lower than Lobell et al. [29] and Kumar et al. [23]. Relative losses are generally higher for higher crop yield potential which is reached when using a higher number of irrigations. Indeed, absolute values of wheat yields are about $30 \%$ higher for all sites for irrigated versus rainfed crops. So, irrigation is important for farmers to increase their productivity. Reducing irrigation under future climate conditions dramatically enhances the yield losses to between $-4 \%$ and $-36 \%$ when considering future limitations in water availability for irrigation. Furthermore, these questions are unfortunately not restricted to India, as for example Egypt is facing similar challenges [2] and exploring potential management strategies [12]. These results raise important questions in terms of food security but also for adaptation strategies and the use of irrigation as mitigation strategy, as irrigation will not necessarily be available to compensate for shortage in water or groundwater depletion due to climate change.

There are limitations related to our modelling experiment. Our experimental design aims at isolating the effects of climate change and water availability, specifically for irrigation. We therefore kept management strategies constant across all sites and time periods and present all results as 19-year averages. However, one drawback with such a generic setup is that we cannot address the adverse effects of local climatic extremes that may occur on smaller scales over short time periods, such as heat extremes, extreme precipitation, droughts and floods. Such events are expected to increase in in this region in the future [42]. Also, future developments and adjustments in management strategies regarding fertilization, herbicides and cultivar choices are to be expected in response to changing climate conditions and will likely be able to counteract some of the adverse changes. Furthermore, other environmental conditions could alter crop growth under future climate change. Conditions that might be particularly important are enhanced $\mathrm{CO}_{2}$ concentrations, that might be expected to increase crop productivity through more efficient photosynthesis [43], whereas increased stress related to crop pests such as insects, plants, and adverse pathogenic agents [8,27] and elevated $\mathrm{O}_{3}$ concentrations [51] will likely decrease crop yields. Elevated $\mathrm{O}_{3}$ and $\mathrm{CO}_{2}$ are particularly interesting due to their interplay with irrigation. Elevated $\mathrm{CO}_{2}$ increases water use efficiency which could reduce the irrigation requirement. Whereas $\mathrm{O}_{3}$ damage to plants is often increased under conditions of irrigation that enhance $\mathrm{O}_{3}$ uptake, which is higher when plants are not under water-stress [33]. By not including these factors in our simulations, we may not consider some of the detrimental effects of the combined effect of stressors. However, this study has highlighted the potential effects of the combination of direct and indirect aspects of climate change on crop yields and food security in the IGP. We encourage more in-depth studies of the combination of known future stressors to help understand and prepare for future challenges.

\section{Acknowledgment}

This study is part of the CIXPAG project funded by the Norwegian Research Council (grant \#244551). It is also co-financed by the Himalayan Climate Change Adaptation Programme (HICAP). HICAP is jointly implemented by the International Centre for Integrated Mountain Development (ICIMOD) in Kathmandu, CICERO Center for International Climate Research in Oslo, and GRID in Arendal, in collaboration with local partners, and is funded by the Norwegian Ministry of Foreign Affairs and the Swedish International Development Agency (SIDA). This work is also part of the project SUSCAP funded by the Norwegian Research Council (grant \#299600/E50). It is part of a European project: the SusCrop - ERA-NET Cofund Action on sustainable crop production. This work has also been funded by another grant from the Norwegian Research Council (grant \#244018). The simulations were performed using the NN9188K project account on resources provided by UNINETT Sigma2 - the National Infrastructure for High Performance Computing and Data Storage in Norway. 


\section{Appendix A}

\section{a. Additional information on the regional climate simulations}

The climate simulations used in this article are using the physical schemes presented in Table A1.

Table A1

Physics schemes used in the WRF model simulations.

\begin{tabular}{lll}
\hline Physics option & Chosen scheme & Reference \\
\hline Radiation & CAM radiation scheme & Collins et al. [1] \\
Microphysics & WSM 6-class graupel scheme & Hong and Lim [4] \\
Cumulus & Kain-Fritsch Scheme & Kain [8] \\
Boundary layer & YSU scheme & Hong et al. [5] \\
Surface layer & Revised MM5 Monin-Obukhov scheme & Jimenez et al. [7] \\
Land surface & Unified Noah land-surface model & Tewari et al. [11] \\
\hline
\end{tabular}

b. Validation of the regional climate simulations

For the historical climate, two types of simulations were initially run with WRF. One simulation called WRF-GFS used initial/boundary conditions from the NCEP/NCAR $2.5^{\circ} \times 2.5^{\circ}$ resolution reanalysis dataset (Kalnay et al. [9]). Another simulation called WRF-CAM used meteorological initial/boundary conditions and sea-surface temperatures from a fully coupled global climate simulation using the National Center for Atmospheric Research (NCAR) Community Earth System Model (CESM1.0.4) (Gent et al. [2]), as described in Hodnebrog et al. [6]. This last configuration was also run for different scenarios.

These simulations are compared in Figure A1 in terms of maximum temperature to other datasets: observations from the Indian Meteorological Department (IMD) and the multi-model ensemble CORDEX (Coordinated Regional Climate Downscaling Experiment; Giorgi et al. [3]). CORDEX is an initiative which arose because of growing needs from society for climate information at regional levels. In CORDEX, several regional climate models are run with initial and boundary conditions from the global models in Coupled Model Intercomparison Project Phase 5 (CMIP5) (Taylor et al. [10]). We have used data from CORDEX South Asia.

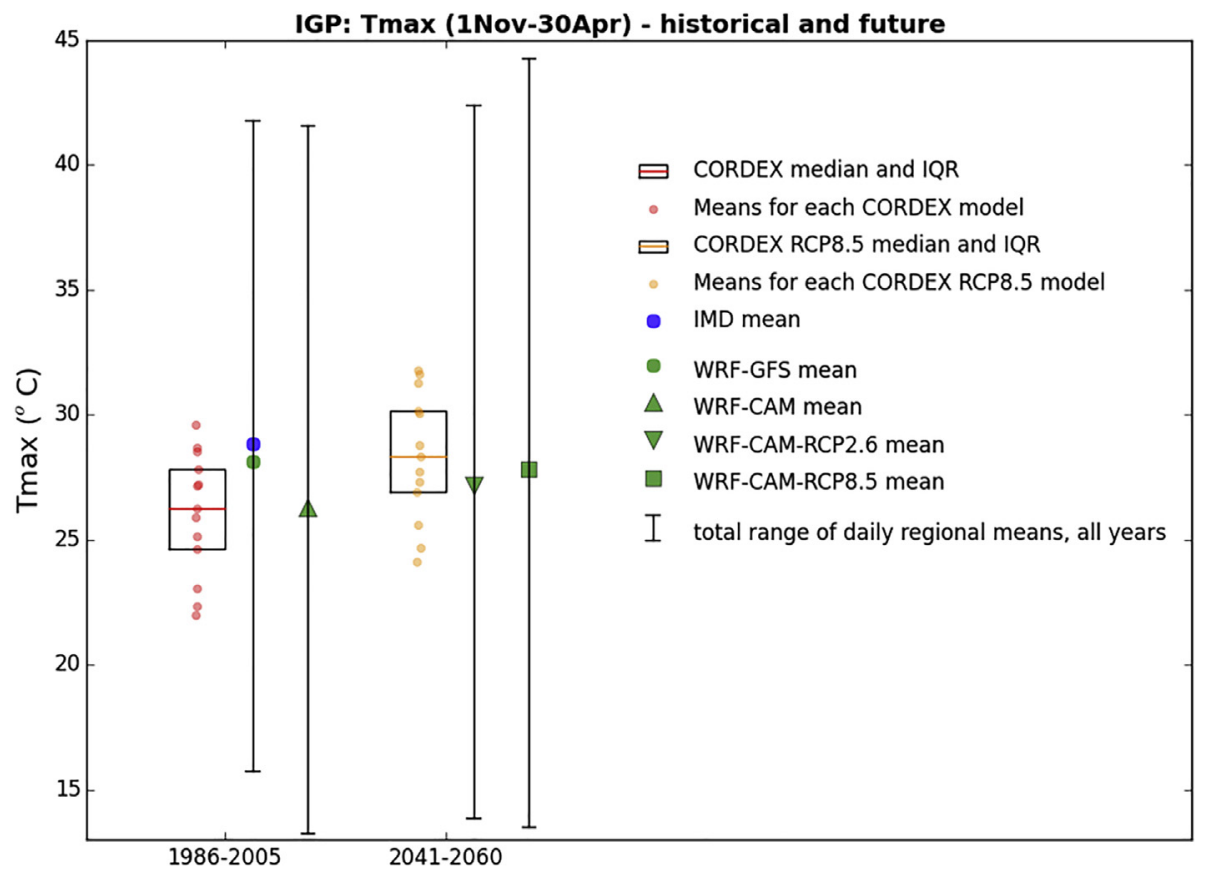

Fig. A1. Box plots of maximum temperature for the CORDEX multi-model ensemble for the present climate (1986-2005) and the future climate under the RCP8.5 scenario (2041-2060).

In the present climate, the simulations realized with WRF (WRF-CAM and WRF-GFS) are compared with the ensemble of models from CORDEX and IMD observations. The results from Figure A1 show that WRF-GFS is very close to IMD and in the range of the results of the CORDEX simulations. WRFCAM is also in the range of CORDEX simulations but not as close to IMD. This still shows that, in the present climate, both types of WRF simulations are reasonable and gives us confidence in our setup. In the future climate (scenario RCP8.5), WRF-CAM is compared with CORDEX. Again, WRF-CAM is in the range of the results of the CORDEX simulations. This shows that the simulations realized with WRF are also reasonable in the future climate and can be used to assess the impact of climate change on temperature and precipitation over the IGP.

\section{c. Additional information on the crop model}

The simulation start date is November 1 for every season, initial conditions include an assumption of previous crop being rice, as a rotation of rice 
and wheat during alternating seasons is common. The generic setup across all seasons and sites includes root weight of $1000 \mathrm{~kg} / \mathrm{ha}$, residue $\mathrm{N} 1 \%$, crop residue of $2000 \mathrm{~kg} / \mathrm{ha}$, incorporation $100 \%$ to a depth of $20 \mathrm{~cm}$. More information on the experimental setup and the plan management of the crop model is presented in Table A2.

Table A2

Experimental setup and plant management.

\begin{tabular}{ll}
\hline Cultivar & HD-2967 and HD-2329 \\
\hline Planting/harvest date & Nov 15, automatic harvest at maturity \\
Start date & November 1 \\
Spacing & 250 seeds $/ \mathrm{m}^{2}, 23 \mathrm{~cm}$ spacing \\
Soil & Deep Sandy Loam, $2 \mathrm{~m}$ \\
Irrigation & $0-6$ irrigations at $70 \mathrm{~mm}$ \\
Fertilizer & $\mathrm{N} 150 \mathrm{~kg} / \mathrm{ha}, \mathrm{P} 60 \mathrm{~kg} / \mathrm{ha}, \mathrm{K} 40 \mathrm{~kg} / \mathrm{ha}$ \\
Herbizide & Pendimathalin, 1 application \\
\hline
\end{tabular}

\section{References for Appendix A}

[1] W.D. Collins et al., 2004. Description of the NCAR Community Atmosphere Model (CAM 3.0). NCAR Tech. Note NCAR/TN-464+STR. 214 pp.Rep.

[2] P.R. Gent, G. Danabasoglu, L.J. Donner, M.M. Holland, E.C. Hunke, S.R. Jayne, D.M. Lawrence, R.B. Neale, P.J. Rasch, M. Vertenstein, P.H. Worley, Z.L. Yang, M.H. and Zhang, 2011. The Community Climate System Model Version 4, J. Clim., 24, 19, 4973-4991, 10.1175/2011jcli4083.1.

[3] F. Giorgi, C. Jones and G. Asrar, 2009. Addressing climate information needs at the regional level: The CORDEX framework, WMO Bulletin, 58, 3 , $175-183$.

[4] S.Y. Hong, and J.O.J. Lim, 2006. The WRF single-moment 6-class microphysics scheme (WSM6), J. Korean Meteor. Soc., 42, $129-151$.

[5] S.Y. Hong, Y. Noh, and J. Dudhia, 2006. A new vertical diffusion package with an explicit treatment of entrainment processes, Mon. Wea. Rev., 134, 2318-2341.

[6] Ø. Hodnebrog, L. Marelle, K. Alterskjær, R.R. Wood, R. Ludwig, E.M. Fischer, T.B. Richardson, P.M. Förster, J. Sillmann, G. Myhre, 2019. Intensification of summer precipitation with shorter time-scales in Europe. Env. Res. Let., vol 14, No. 12, https://doi.org/10.1088/1748\&ndash;93 26/ab549c.

[7] P.A. Jimenez, J. Dudhia, J. Fidel Gonzalez-Rouco, J. Navarro, M. J. P., and E. Garcia-Bustamante, 2012. A revised scheme for the WRF surface layer formulation, Mon. Wea. Rev., 140, 898-918.

[8] J.S. Kain, 2004. The Kain-Fritsch convective parameterization: An update. J. Appl. Meteor., 43, 170-181. doi:10.1175/15200450(2004043<0170:TKCPAU >2.0.CO; 2)

[9] E. Kalnay, M. Kanamitsu, R. Kistler, W. Collins, D. Deaven, L. Gandin, M. Iredell, S. Saha, G. White, J. Woollen, Y. Zhu, M. Chelliah, W. Ebisuzaki, W. Higgins, J. Janowiak, K.C. Mo, C. Ropelewski, J. Wang, A. Leetmaa, R. Reynolds, R. Jenne and D. Joseph, 1996. The NCEP/NCAR 40-year reanalysis project, Bull. Amer. Meteorol. Soc., 77, 3, 437-471, 10.1175/1520-0477(1996)077<0437:tnyrp>2.0.co; 2, 1996.

[10] K.E. Taylor, R.J. Stouffer, and G.A. Meehl, 2011. An Overview of CMIP5 and the Experiment Design, Bull. Amer. Meteorol. Soc., 93, 4, 485-498, 10.1175/BAMS-D-11-00094.1.

[11] M. Tewari, F. Chen, W. Wang, J. Dudhia, M. A. LeMone, K. Mitchell, M. Ek, G. Gayno, J. Wegiel, and R. H. Cuenca, 2004. Implementation and verification of the unified NOAH land surface model in the WRF model. 20th conference on weather analysis and forecasting/16th conference on numerical weather prediction, 11-15.

\section{References}

[1] M.G. M Ali, M.M. Ibrahim, A. El Baroudy, et al., Climate change impact and adaptation on wheat yield, water use and water use efficiency at North Nile Delta, Front. Earth Sci. 14 (2020) 522-536, https://doi.org/10.1007/s11707-019-0806-4.

[2] S. Asseng, A.M. S Kheir, B.T. Kassie, G. Hoogenboom, A.I.N. Abdelaal, D.Z. Haman, A.C. Ruane, Can Egypt become self-sufficient in wheat? ERL 13 (9) (2018) https:// doi.org/10.1088/1748-9326/aada50.

[3] S. Asseng, F. Ewert, P. Martre, et al., Rising temperatures reduce global wheat production, Nat. Clim. Change 5 (2015) 143-147, https://doi.org/10.1038/ nclimate 2470

[4] S.D. Attri, L.S. Rathore, Simulation of impact of projected climate change on wheat in India, Int. J. Climatol.: A J. R. Meteorol. Soc. 23 (6) (2003) 693-705.

[5] P.K. Aggarwal, P.K. Joshi, J.S. I Ingram, R.K. Gupta, Adapting food systems of the Indo-Gangetic plains to global environmental change: key information needs to improve policy formulation, Environ. Sci. Pol. 7 (2004) 487-498.

[6] M.S. Babel, P. Deb, P. Soni, Performance evaluation of Aquacrop and DSSAT-CERES for maize under different irrigation and manure application rates in the Himalayan region of India, Agric. Res. 8 (2018) 207, https://doi.org/10.1007/s40003-0180366-y.

[7] P.K. Bal, A. Ramachandran, K. Palanivel, et al., Climate change projections over India by a downscaling approach using PRECIS, Asia-Pacific, J. Atmos. Sci. 52 (2016) 353-369, https://doi.org/10.1007/s13143-016-0004-1.

[8] M. Barzman, P. Bàrberi, A.N.E. Birch, et al., Eight principles of integrated pest management, Agron. Sustain. Dev. 35 (2015) 1199, https://doi.org/10.1007/ s13593-015-0327-9.

[9] B.S. Chauhan, B. Singh, Prabhjyot-Kaur, G. Mahajan, R.K. Randhawa, H. Singh, M.S. Kang, Global warming and its possible impact on agriculture in India, Adv.
Agron. 123 (2014) 65-121, https://doi.org/10.1016/B978-0-12-420225-2.000029. Elsevier.

[10] R.K. Chaturvedi, J. Joshi, M. Jayaraman, G. Bala, N.H. Ravindranath, Multi-model climate change projections for India under representative concentration pathways, Curr. Sci. 103 (7) (2012) 791-802.

[11] S.K. Dash, M.A. Kulkarni, U.C. Mohanty, K. Prasad, Changes in the characteristics of rain events in India, J. Geophys. Res. 114 (2009) D10109, https://doi.org/ 10.1029/2008JD010572.

[12] S. Ding, E.F. Ali, A.M. Elmahdy, K.E. Ragab, M.F. Seleiman, A.M.S. Kheir, Modeling the combined impacts of deficit irrigation, rising temperature and compost application on wheat yield and water productivity, Agric. Water Manag. 244 (2021), https://doi.org/10.1016/j.agwat.2020.106626.

[13] Directorate of Economics and Statistics, Pocket Book of Agricultural Statistics 2016, Government of India, Ministry of Agriculture and Farmers Welfare, Department of Agriculture, Cooperation and Farmers Welfare, Directorate of Economics and Statistics, New Delhi, 2017. http://eands.dacnet.nic.in/PDF/Agricultural_Statistics_ 2016.pdf.

[14] Directorate of wheat development, Status Paper on Wheat, Directorate of wheat development, Ministry of Agriculture, Department of Agriculture and Cooperation, Ghaziabad (UP), India, 2015.

[15] J.M.A. Duncan, J. Dash, P.M. Atkinson, Elucidating the impact of temperature variability and extremes on cereal croplands through remote sensing, Global Change Biol. 21 (4) (2015) 1541-1551, https://doi.org/10.1111/gcb.12660.

[16] P.R. Gent, G. Danabasoglu, L.J. Donner, M.M. Holland, E.C. Hunke, S.R. Jayne, D.M. Lawrence, R.B. Neale, P.J. Rasch, M. Vertenstein, P.H. Worley, Z.L. Yang, M.H. Zhang, The community climate system model version 4, J. Clim. 24 (19) (2011) 4973-4991, https://doi.org/10.1175/2011jcli4083.1.

[17] A.K. Gosain, et al., Climate change impact assessment on hydrology of Indian river basins, Curr. Sci. 90 (3) (2006), 10 February 346-35. 
[18] Ø. Hodnebrog, L. Marelle, K. Alterskjær, R.R. Wood, R. Ludwig, E.M. Fischer, T.B. Richardson, P.M. Forster, J. Sillmann, G. Myhre, Intensification of summer precipitation with shorter time-scales in Europe, Environ. Res. Lett. 14 (12) (2019), https://doi.org/10.1088/1748-9326/ab549c.

[19] G. Hoogenboom, C.H. Porter, K.J. Boote, V. Shelia, P.W. Wilkens, U. Singh, J.W. White, S. Asseng, J.I. Lizaso, L.P. Moreno, W. Pavan, R. Ogoshi, L.A. Hunt, G.Y. Tsuji, J.W. Jones, The DSSAT crop modeling ecosystem, in: K.J. Boote (Ed.), Advances in Crop Modeling for a Sustainable Agriculture, Burleigh Dodds Science Publishing, Cambridge, United Kingdom, 2019, pp. 173-216, https://doi.org/ 10.19103/AS.2019.0061.10.

[20] G. Hoogenboom, C.H. Porter, V. Shelia, K.J. Boote, U. Singh, J.W. White, L.A. Hunt R. Ogoshi, J.I. Lizaso, J. Koo, S. Asseng, A. Singels, L.P. Moreno, J.W. Jones, Decision Support system for Agrotechnology transfer (DSSAT) version 4.7, DSSAT Foundation, Gainesville, Florida, USA, 2019, p. 5. https://DSSAT.net.

[21] J.W. Jones, G. Hoogenboom, C.H. Porter, K.J. Boote, W.D. Batchelor, L.A. Hunt, P.W. Wilkens, U. Singh, A.J. Gijsman, J.T. Ritchie, DSSAT cropping system model, Eur. J. Agron. 18 (2003) 235-265.

[22] M. Kumar, R.K. Pannu, R. Singh, B. Sign, A.K. Dhaka, Rajeev, Prediction of growth and yield of late sown wheat using DSSAT (v4.5) model under western zone of Harayana, Int. J. Curr.Microbiol. Appl. Sci. 6 (3) (2017) 1687-1696. ISSN: 2319 7706 .

[23] S.N. Kumar, P.K. Aggarwal, D.N. Swaroopa Rani, R. Saxena, N. Chauhan, S. Jain, Vulnerability of wheat production to climate change in India, Clim. Res. 59 (3) (2014) 173-187, https://doi.org/10.3354/cr01212.

[24] J.K. Ladha, J.E. Hill, J.M. Duxbury, et al., Sustainability of post-green revolution agriculture: the rice-wheat cropping systems of the indo-gangetic plains and China, in: J.K. Ladha, J.E. Hill, J.M. Duxbury, R.K. Gupta, R.J. Buresh, doi (Eds.), Improving the Productivity and Sustainability of Rice-Wheat Systems: Issues and Impacts, 2003, https://doi.org/10.2134/asaspecpub65.c1.

[25] B. Lalic, J. Eitzinger, D.T. Mihailovic, S. Thaler, M, Jancic, Climate change impacts on winter wheat yield change - which climatic parameters are crucial in Pannonian lowland? J. Agric. Sci. 151 (6) (2012) 757-774.

[26] M. Lal, K.K. Singh, L.S. Rathore, G. Srinivasan, S.A. Saseendran, Vulnerability of rice and wheat yields in NW India to future changes in climate, Agric. For. Meteorol. 89 (2) (1998) 101-114.

[27] J.R. Lamichhane, M. Barzman, K. Booij, P. Boonekamp, N. Desneux, L. Huber, P. Kudsk, S.R.H. Langrell, A. Ratnadass, P. Ricci, J.-.L. Sarah, A. Messean, Robust cropping systems to tackle pests under climate change, A review. Agron. Sustain. Dev. 35 (2015) 443-459, https://doi.org/10.1007/s13593-014-0275-9.

[28] D.L. Liu, G.J. O'Leary, B. Christy, I. Macadam, B. Wang, M.R. Anwar, A. Weeks, Effects of different climate downscaling methods on the assessment of climate change impacts on wheat cropping systems, Climatic Change 144 (4) (2017) 687-701.

[29] D.B. Lobell, A. Sibley, J.I. Ortiz-Monasterio, Extreme heat effects on wheat senescence in India, Nat. Clim. Change 2 (3) (2012) 186-189, https://doi.org/ 10.1038/nclimate1356.

[30] A. Lutz, W. Immerzeel, A. Shrestha, A, et al., Consistent increase in High Asia's runoff due to increasing glacier melt and precipitation, Nat. Clim. Change 4 (2014) 587-592, https://doi.org/10.1038/nclimate2237.

[31] Z. Lv, X. Liu, W. Cao, Y. Zhu, Climate change impacts on regional winter wheat production in main wheat production regions of China, Agric. Meteorol. 171-172 (2013) 234-248.

[32] A. Mezghani, Ø. Hodnebrog, R.E. Benestad, J. Sillmann, F. Stordal, K.M. Parding, Projected mean temperatures over India based on simulations from dynamical and statistical downscaling, Int. J. Climatol. (2020) (In preparation, personal communication).

[33] G. Mills, K. Sharps, D. Simpson, et al., Closing the global ozone yield gap, Quantification and cobenefits for multistress tolerance, Global Change Biol. 24 (2018) 4869-4893, https://doi.org/10.1111/gcb.14381.

[34] S.C. Mishra, S.K. Singh, R. Patil, N. Bhusal, A. Malik, S. Sareen, Breeding for heat tolerance in wheat, in: R.S. Shukla, P.C. Mishra, R. Chatrath, R.K. Gupta,
S.S. Tomar, Indu Sharma (Eds.), WHEAT: Recent Trends on Production Strategies of Wheat in India, DWR, Karnal, 2014, pp. 15-29.

[35] A. Mishra, S.C. Liu, Changes in precipitation pattern and risk of drought over India in the context of global warming, J. Geophys. Res.: Atmosphere 119 (13) (2014) 7837-7841, https://doi.org/10.1002/2014JD021471.

[36] R. Ortiz, K.D. Sayre, B. Govaerts, R. Gupta, G.V. Subbarao, T. Ban, D. Hodson, J.M. Dixon, J. Iván Ortiz-Monasterio, M. Reynolds, Climate change: can wheat beat the heat? Agriculture, Ecosystems \& Environment 126 (1-2) (2008) 46-58, https:// doi.org/10.1016/j.agee.2008.01.019.

[37] P. Paymard, F. Yaghoubi, M. Nouri, M. Bannayan, Projecting climate change impacts on rainfed wheat yield, water demand, and water use efficiency in northeast Iran, Theor. Appl. Climatol. 138 (3-4) (2019) 1361-1373.

[38] A. Rani, K.K. Bandyopadhyay, P. Krishnan, Simulation of nitrogen uptake, nitrogen utilization efficiency and yield of wheat under tillage, residue and nitrogen management using dssat-ceres-wheat model, Indian J. Ecol. 44 (2) (2017) 167-178.

[39] J. Sanjay, R. Krishnan, A.B. Shrestha, R. Rajbhandari, G.-Y. Ren, Downscaled climate change projections for the hindu kush himalayan region using CORDEX South Asia regional climate models, Adv. Clim. Change Res. 8 (3) (2017) 185-198, https://doi.org/10.1016/j.accre.2017.08.003.

[40] D.C. Saxena, S.V. Sai Prasad, R. Parashar, I. Rathi, Phenotypic characterization of specific adaptive physiological traits for heat tolerance in wheat, Indian J. Plant Physiol. 21 (3) (2016) 318-322, https://doi.org/10.1007/s40502-016-0241-4.

[41] I. Sekar, S. Pal, Rice and wheat productivity in the Indo-Gangetic Plain of India: changing pattern of growth and future strategies, Indian J. Agric. Econ. 67 (2012) 238-252.

[42] J. Sillmann, V.V. Kharin, F.W. Zwiers, X. Zhang, D, Bronaugh, Climate extremes indices in the CMIP5 multimodel ensemble: Part 2. Future climate projections, J. Geophys. Res. Atmos. 118 (2013) 2473-2493, https://doi.org/10.1002/ jord.50188.

[43] A.J. Simkin, P.E. López-Calcagno, C.A. Raines, Feeding the world: improving photosynthetic efficiency for sustainable crop production, J. Exp. Bot. 70 (4) (2019) 1119-1140, https://doi.org/10.1093/jxb/ery445, 1 February 2019.

[44] W.C. Skamarock, J.B. Klemp, A time-split nonhydrostatic atmospheric model for weather research and forecasting applications, J. Comput. Phys. 227 (7) (2008) 3465-3485, https://doi.org/10.1016/j.jcp.2007.01.037, 2008.

[45] N. Subash, H.S. Mohan, Evaluation of the impact of climatic trends and variability in rice-wheat system productivity using Cropping System Model DSSAT over the Indo-Gangetic Plains of India, Agric. For. Meteorol. 164 (2012) 71-81, https:// doi.org/10.1016/j.agrformet.2012.05.008.

[46] D.P. van Vuuren, J. Edmonds, M. Kainuma, K. Riahi, A. Thomson, K. Hibbard, G.C. Hurtt, T. Kram, V. Krey, J.F. Lamarque, T. Masui, M. Meinshausen, N. Nakicenovic, S.J. Smith, S.K. Rose, The representative concentration pathways: an overview, Climatic Change 109 (1-2) (2011) 5-31, https://doi.org/10.1007/ s10584-011-0148-z,2011.

[47] J. Wu, Y. Xu, X.-J. Gao, Projected changes in mean and extreme climates over hindu kush himalayan region by 21 CMIP5 models, Adv. Clim. Change Res. 8 (3) (2017) 176-184, https://doi.org/10.1016/j.accre.2017.03.001.

[48] M.N. Zacharias, S.D. Singh, D.N. Swaroopa Rani, P.K. Aggarwal, Assessment of impacts of climate change on rice and wheat in the Indo-Gangetic plains, Journal of Agrometeorology 16 (1) (2014) 9-17.

[49] E.B. Zaveri, D. Lobell, The role of irrigation in changing wheat yields and heat sensitivity in India, Nat. Commun. 10 (2019) 4144, https://doi.org/10.1038/ s41467-019-12183-9.

[50] C. Zhao, B. Liu, S. Piao, D.B. Lobell, Y. Huang, et al., Temperature increase reduces global yields of major crops in four independent estimates, Proc. Natl. Acad. Sci. U.S.A. 114 (2017), https://doi.org/10.1073/pnas.1701762114, 9326-31.

[51] A. Sharma, G. Beig, N. Ojha, S.S. Gunthe, Revisiting the Crop Yield Loss in India Attributable to Ozone, Atmospheric Environment, 2019. DOI:10.016/ j.aeaoa.100008. 